\title{
Population estimate and rate of increase of southern right whales Eubalaena australis in southeastern Australia
}

\author{
K. Stamation ${ }^{1, *}$, M. Watson ${ }^{2}$, P. Moloney ${ }^{1}$, C. Charlton ${ }^{3}$, J. Bannister ${ }^{4,+}$ \\ ${ }^{1}$ Arthur Rylah Institute for Environmental Research, Department of Environment, Land, Water and Planning, Heidelberg, \\ Victoria 3018, Australia \\ ${ }^{2}$ Barwon South West Regional Services, Department of Environment, Land, Water and Planning, Warrnambool, \\ Victoria 3280, Australia \\ ${ }^{3}$ Centre for Marine Science and Technology, Curtin University, Bentley, Western Australia 6102, Australia \\ ${ }^{4}$ Western Australian Museum, Welshpool, Western Australia 6106, Australia
}

\begin{abstract}
In Australian waters, southern right whales Eubalaena australis form 2 genetically distinct populations that have shown contrasting patterns of recovery since whaling ceased: a western population in South Australia and Western Australia and an eastern population in southeastern Australia (Tasmania, Victoria and New South Wales). Here, we provide an abundance estimate derived from a breeding female superpopulation mark-recapture model for the southeastern southern right whale population. The population comprises 268 individuals (68 breeding females) and has increased at a rate of $4.7 \%$ per annum between 1996 and 2017 . There has been no significant change in the annual abundance of mother-calf pairs sighted at the only calving ground (Logans Beach in Victoria) over the last 3 decades. The total number of southern right whales (i.e. all adults and calves) using the southeastern Australian coastline has increased by $7 \%$ since 1985. Unlike the population estimate (which was restricted to breeding females sighted prior to the post-breeding southward migration), this estimate is likely to include transiting whales from the southwestern population. The theoretical population model predicts 19 breeding females at Logans Beach in 2018 and 28 in 2028; the actual number of breeding females, as of 2018, is 14 . This study provides the first complete estimate of population size and rate of increase of southern right whales along the southeastern Australian coastline. This knowledge is critical for assessing population status and recovery of southern right whales in Australia. It provides a basis for monitoring persistence and responses of the population to environmental stressors.
\end{abstract}

KEY WORDS: Southern right whale $\cdot$ Eubalaena australis $\cdot$ Calving ground $\cdot$ Population estimate $\cdot$ Photo-identification $\cdot$ Logans Beach

\section{INTRODUCTION}

Southern right whales Eubalaena australis were targeted for commercial hunting between 1790 and 1980, with at least 150000 killed globally (Jackson et al. 2008). In New Zealand and southeastern Australia, over 58000 southern right whales were taken (Carroll et al. 2014). Although the species is now increasing in number, differences in population size

${ }^{*}$ Corresponding author: kasey.stamation@delwp.vic.gov.au ${ }^{ \pm}$Deceased and estimated rate of increase have been observed between the southwestern (Western Australia and South Australia) and southeastern (Victoria, New South Wales and Tasmania) Australian regions (Watson et al. 2015, Bannister 2018).

Evidence of genetic differentiation in mitochondrial and microsatellite DNA haplotype frequencies between the 2 regions led to the delineation of distinct southwestern and southeastern Australian

(C) The authors 2020. Open Access under Creative Commons by Attribution Licence. Use, distribution and reproduction are unrestricted. Authors and original publication must be credited. 
management units (Carroll et al. 2011a). More recent work, however, has shown the situation to be more complex, providing evidence of whales from different calving grounds mixing in the migratory corridors, which may lead to gene flow between these management units (Carroll et al. 2015). Carroll et al. (2011a, 2015) found no genetic distinction between southern right whales in New Zealand and those at Logans Beach, Victoria, the only recognised southeastern Australian calving ground. Carroll et al. (2011a, 2015) hypothesised that some whales from the New Zealand population may be migrating to southeastern Australia or that whales from the 2 regions mix in the Tasman Sea.

The size of the southwestern southern right whale management unit was estimated via annual coastal aerial surveys at around 3191 whales in 2018 (Smith et al. 2019), and strong population growth was observed between 1993 and 2018 ( 6\% per annum; Bannister 2018, Smith et al. 2019). There have been no population estimates for the southeastern management unit, apart from a preliminary estimate of 257 whales based on coastal aerial surveys over 2 seasons (Watson et al. 2015) and Kemper et al. (1997) who identified 54 adults (including 22 breeding females) from aerial surveys between 1991 and 1993. While southern right whales are listed as Least Concern under the International Union for Conservation of Nature Red List and endangered under the Australian Government Environment Protection and Biodiversity Conservation Act 1999, they are considered critically endangered in Victoria (Victorian Department of Sustainability and Environment 2013). The only area where mother-calf pairs are seen regularly is off Logans Beach in southwestern Victoria (DSEWPaC 2012). The national conservation management plan for the southern right whale (DSEWPaC 2012) emphasises the need to better understand population recovery in eastern Australia and differences between the southeastern and southwestern populations. Having a reliable estimate of the current abundance and rate of increase of the population, as well as usage patterns at the Logans Beach breeding ground, is crucial for monitoring the longterm persistence of this population and its responses to anthropogenic factors and other environmental stressors.

Two datasets currently exist for southern right whales in southeastern Australia: (1) a southern right whale sightings database for Victoria that includes $>3000$ incidental sighting records collected since 1985 and (2) the South East Australian Southern
Right Whale Photo Identification Catalogue (SEA SRW PIC) containing >1000 images of 366 individual whales sighted between 1993 and 2017 in South Australia, Victoria, Tasmania and New South Wales. In addition, the Australasian Right Whale Photo Identification Catalogue (ARWPIC) was established to facilitate the comparison and storage of images from Australia and New Zealand (R. Pirzl et al. unpubl.; information available from www.skadia. com.au). SEA SRW PIC images have now been added to ARWPIC.

Here, we use observation data from the ARWPIC, SEA SRW PIC and the Victorian southern right whale sightings databases and a superpopulation markrecapture model to provide estimates of abundance and rate of increase for southern right whales in southeastern Australia. Such superpopulation markrecapture models have been used to estimate population numbers of southern right whales in New Zealand (Carroll et al. 2011b), humpback whales Megaptera novaeangliae in Ecuador (Félix et al. 2011) and Alaska (Teerlink et al. 2015) and spinner dolphins Stenella longirostris in Hawaii (Tyne et al. 2014). We also report on the relative abundance of mother-calf pairs at Logans Beach, Victoria, over the last 3 decades. This study specifically aims to test whether the southeastern southern right whale population is showing signs of recovery and is the first synthesis of data for this population since records began in the mid-1980s. We also aim to provide a theoretical population model of breeding females at Logans Beach which we can use to compare observed and expected values over time. Implications for management and the need for further research are discussed.

\section{MATERIALS AND METHODS}

\subsection{Photo-identification data}

Photo-identification is a non-invasive method that can be used to investigate the distribution, movement and population trends of cetaceans. Southern right whales have unique callosity patterns (patches of thickened, keratinised tissue) that allow for the photo-identification of individuals (Payne et al. 1983, Bannister 1990, Best 1990, Burnell 2001). The SEA SRW PIC was established in 2001 and includes images from 1993 onwards in southeastern Australia, including South Australia (east of Ceduna), Victoria, Tasmania and New South Wales. These photos were collected during systematic photo-identifica- 
tion flights and aerial surveys (Watson et al. 2015), during opportunistic whale monitoring and sightseeing flights, and by members of the public from landbased and vessel-based platforms. Only whales with images suitable for photo-identification were included in the catalogue.

Features of each whale's callosity pattern were coded and other conspicuous markings (such as belly blazes) were noted. Image quality was variable but images were retained when callosity patterns could be coded with certainty. These data, along with their associated metadata, were stored in a Microsoft Access database containing a coding-based matching system known as BigFish (www.skadia.com.au/resources). Each sighted whale was cross-checked against existing images using the BigFish CodeCompare feature (R. Pirzl et al. unpubl.; information available from www.skadia.com.au). If a match existed, the sighting was added to the catalogue; otherwise, it was catalogued as a new individual.

The SEA SRW PIC was cross-referenced against the ARWPIC in 2016. When the SEA SRW PICARWPIC matching took place, the SEA SRW PIC contained images of 343 whales and the ARWPIC contained images of 1576 whales sighted in southwestern Australia between 1978 and 2011 (catalogued by J. Bannister). ARWPIC already included the data from 109 individuals from southeastern Australia (sighted in Tasmania between 2011 and 2014). Therefore these whales were excluded from the SEA SRW PIC-ARWPIC matching. Cross-referencing of the remaining 234 whales in the SEA SRW PIC was performed as per the matching protocol described in the ARWPIC user guide (www.youtube.com/watch? $\mathrm{v}=$ fadf1eOMzi4).

The matching protocol involved a 6-step search process, starting with the tightest search (i.e. selecting the maximum number of features with information) and then broadening the search by removing features at each step. Due to time constraints, we did not perform all 6 searches available in the ARWPIC for each whale, although at least the first 3 searches were performed for all individuals. This approach was considered appropriate given that searches 4 to 6 returned whales with callosities that had been coded differently or were not seen; therefore, the chances of being able to make a positive identification with a high degree of confidence were low in the last searches. All matches and new individuals were validated by a minimum of 2 experienced photo-identification experts. Known breeding females from Logans Beach were also cross-referenced against additional southwestern photo-identification catalogues from the Head of the Bight and Fowlers Bay in South Australia.

\subsection{Sightings data}

Southern right whale sighting records at Logans Beach $\left(38.404^{\circ} \mathrm{S}, 142.521^{\circ} \mathrm{E}\right)$ have been collected and maintained by Victorian Government staff since 1985. Because of the creation of the southeastern Australian southern right whale photo-identification network, sightings from across Victoria, New South Wales and South Australia were also included from the early 2000s. We used data collected until 2018, totalling 375 individual whales for the southeastern Australian region. Data collectors (observers) included Victorian Government staff, whale-watching volunteers at the Logans Beach whale-watching platform, whale-watching tour operators, local government employees and members of the public. The minimum observation data collected were date, time, location, reproductive status (where calves were observed) and number of whales (with minimum and maximum values when numbers were uncertain). Since 2007, consistent observations have been made by one volunteer whale-watcher at the Logans Beach whale-watching platform for a minimum of $6 \mathrm{~h} \mathrm{~d}^{-1}$ during the whale-watching season (April/May to September/October). This observer recorded all whale sightings (including behavioural observations) every 30 min each day during the entire season.

All data were housed in a relational database and underwent quality assurance checks to ensure consistency and accuracy in the dataset. Only data validated by images or obtained from reliable and experienced observers were included in the analyses.

\subsection{Statistical analysis}

\subsubsection{Superpopulation mark-recapture model}

The population of southern right whales in southeastern Australia was estimated using a photo-identification mark-recapture model and the sighting data from the ARWPIC and SEA SRW PIC databases. Two superpopulation mark-recapture models were explored: one including all southern right whales detected on the southeastern Australian coastline and one based on breeding females from the southeastern Australian population. The data used in the first superpopulation mark-recapture model (i.e. all detections) were restricted to the period between 1993 and 
2011, the years in which we had data from both the southwestern and southeastern region. The second superpopulation mark-recapture model (i.e. southeastern Australian breeding females) relied on data collected between 1985 and 2017. To minimise the chance of erroneously including breeding females migrating within a season from the southwestern to the southeastern management unit, we only included breeding females detected in southeastern Australia before 1 September each year (i.e. the start of postbreeding southward migration).

We used a POPAN superpopulation mark-recapture model, a parameterisation of the Jolly-Seber model in terms of a superpopulation and the probability of entry into a population (Schwarz \& Arnason 1996). The model allows for an open population that can grow with births and immigration and decline with deaths and permanent emigration. Capture probabilities are modelled with covariates so that transience can be accounted for, allowing for breeding females to be absent for different periods of time rather than a fixed $3 \mathrm{yr}$ interval. The model includes apparent survival from one year to the next $(\varphi)$, capture probability $(\mathrm{p})$, probability of entry into the population $(\beta)$ and the superpopulation $(N)$ separated by sex status (female or unknown). The superpopulation includes an estimate of the number of animals never captured and our model allowed for the probability of entry and capture to vary between years. Search effort was assumed to be constant across years as there was no reliable measure of effort prior to 2007 and search effort was only available at Logans Beach from 2007 onwards. Other assumptions of the superpopulation model are that all individuals have an equal probability of capture, given they are in the search zone; all individuals in the same age class have the same survival rate; and all individuals are uniquely marked and correctly identified.

The superpopulation mark-recapture model was constructed in a Bayesian framework and parameters were estimated with the package R2jags ( $\mathrm{Su} \&$ Yajima 2012) in R version 3.4.4 (R Core Team 2018). A single model was fit to each dataset and naïve prior distributions were used. The prior distributions used in the model and histograms of the posterior distributions are shown in Tables S1 \& S2, Fig. S1, respectively (see Supplement 1 at www.int-res.com/articles/ suppl/n041p373_supp/). Three chains were used with 120000 iterations each, a burn in of 40000 and a thinning rate of 10 . Models were considered to have converged if they satisfied visual inspection and the Gelman Rubin statistic was less than 1.1 (Brooks \& Gelman 1998). Mean growth rate was estimated using the posterior distribution of the estimated number of living whales in each year. Code for how this model was implemented is provided in Supplement 2 at www.int-res.com/articles/suppl/n041p373_supp/.

\subsubsection{Bayesian sightings trend model}

The minimum number of southern right whales observed in southeastern Australia was modelled using a negative binomial generalised linear model in a Bayesian framework (Zuur et al. 2007, Kéry 2010). Two models were investigated, one based on the entire southeastern Australian dataset and one based on the breeding females-only dataset, as described in the previous section. Sighting data were sourced from the Logans Beach sighting database and the SEA SRW PIC. Data were grouped by date, observer, time and the minimum number of whales summed. The minimum number of southern right whales (and mother-calf pairs) for each year was calculated using either the maximum number of southern right whales (or mother-calf pairs) seen at the same time throughout the year or the number of individually recognised southern right whales for the year, whichever was highest. Year was considered as a linear fixed effect and if the coefficient was positive, we inferred that the overall southern right whale and/or mother-calf pair population visiting the region increased over time. To investigate trends in mother-calf pairs at Logans Beach, only mother-calf pairs for which the female was known to display calving-site fidelity to Logans Beach were included (M. Watson unpubl. data).

Analyses were conducted with the brms package in R (Bürkner 2017). Four chains were used with 12000 iterations each and a burn in of 4000 . No thinning was conducted. Models used naïve priors and were considered to have converged if they satisfied visual inspection and the Gelman Rubin statistic was less than 1.1 (Brooks \& Gelman 1998). The prior distributions used in the model and histograms of the posterior distributions are shown in Table S3 and Fig. S3 in Supplement 1, respectively.

\subsubsection{Theoretical population model}

A structured population model following individual breeding females (Caswell \& John 1992) at Logans Beach was constructed based on observed calving intervals at Logans Beach (M. Watson unpubl. data) and population parameters from the 
literature. This model can be used as a tool to compare actual growth rates to typical growth rates seen elsewhere. The discrete time model followed the fate of individual whales from birth to death. Survival rates for juveniles were taken from Carroll et al.'s (2016) study in New Zealand and estimated to be $0.87 \pm 0.17$ (mean $\pm \mathrm{SE}$ ) for the first year and $0.95 \pm 0.05$ per annum until reproductive maturation at $9 \mathrm{yr}$. The female survival rate used for mature southern right whales (>9 yr) was $0.988 \pm 0.001$ per annum, based on Brandão et al.'s (2013) estimate of post-first-year female survival for southern right whales in South Africa. Time between births for breeding females was modelled using the empirical distribution of calving intervals from the observational data from Logans Beach (M. Watson unpubl. data). The sex of each individual was assigned at birth. A flow diagram for the model process is shown in Fig. 1. The model was run from 1980 to 2028 to estimate population growth over time. Scenarios of different initial populations (from 1 to 15 females) were explored. Model simulations were run 1000 times for each scenario. The observed mean, median and 95\% credible intervals for the population were estimated. The code used to run these simulations can be found in Supplement 3 at www.int-res.com/articles/suppl/n041p373_supp/.

\section{RESULTS}

\subsection{Superpopulation mark-recapture model}

The total number of individual southern right whales identified in southeastern Australia in a season increased from 3 in 1993 to 27 in 2011 (the years data was available for the both the southeastern and the southwestern population), with a total of 199 individuals identified across those years. From 1993 to 2017 , 368 individuals were identified. The average number of individuals sighted per year was 18, with up to 60 individuals sighted in a single season (2013). Results

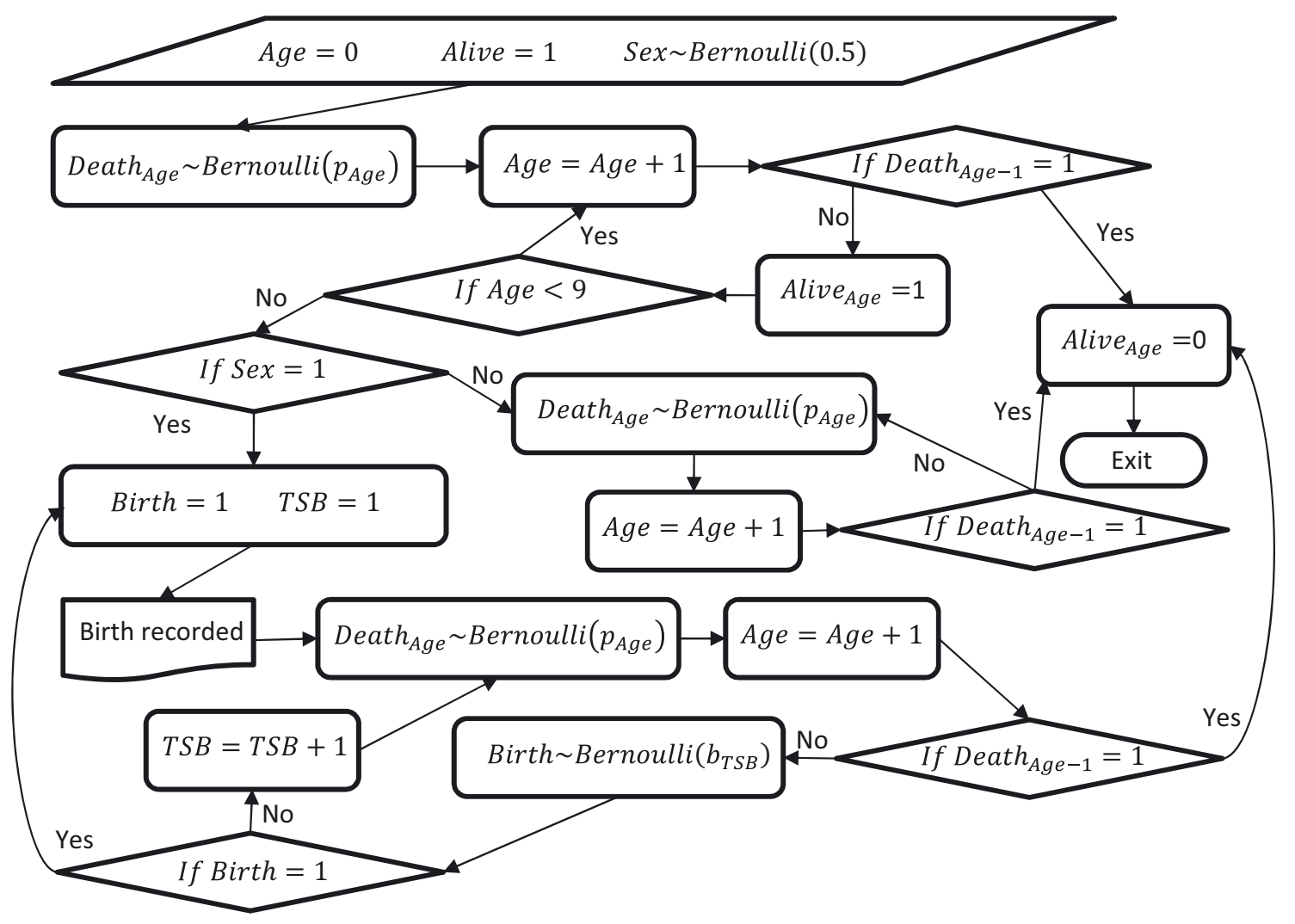

Fig. 1. Flow diagram for an individual whale in the structured population model. Age is the age of the female whale. Alive $e_{\text {Age }}$ is 1 if the individual is alive at that age and 0 otherwise. Sex is 1 if the whale is female and 0 if Male. Death Age $_{\text {is }} 1$ if the individual died at that age. Birth is 1 in years where the female has a calf, and zero otherwise. TSB is the number of years since the last calf was born. $p_{A g e}$ is the mortality rate at that age from the literature. $b_{T S B}$ is the probability that a female will have a birth given the time since last birth using data collected at Logans Beach 


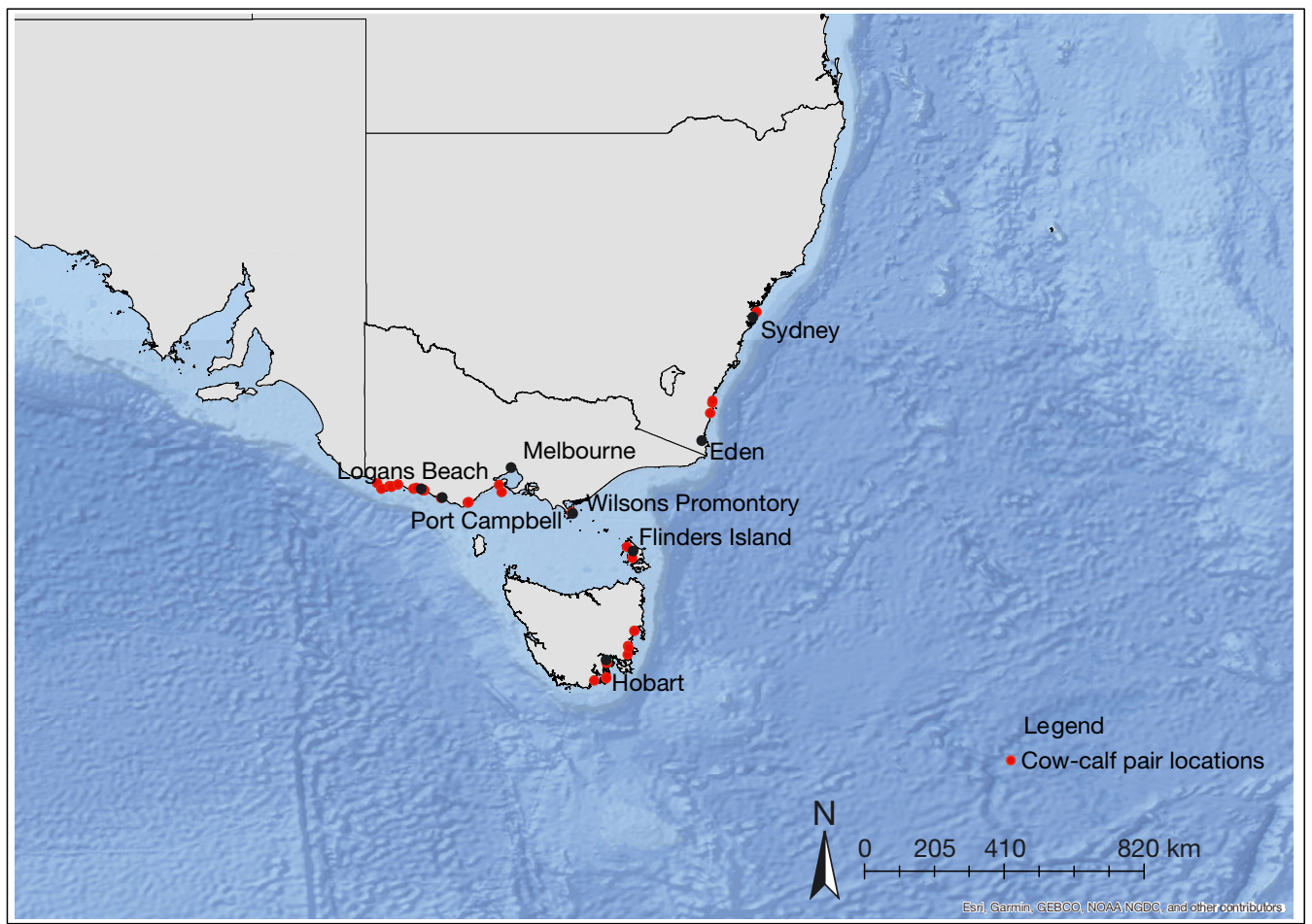

Fig. 2. Location of mother-calf pairs identified in southeastern Australian waters prior to 1 September of each year (1993-2017)

from the first superpopulation mark-recapture model which included all individuals are not presented here as the model did not converge and results were deemed unreliable. This was likely due to the high number of individuals that were only sighted once. Limitations of the model are further developed in Section 4.

Restricting the model to breeding females sighted in southeastern Australia produced more reliable results. Between 1993 and 2017, a total of 37 individual females with calves were identified in southeastern Australia prior to 1 September. Twenty of these were west of Warrnambool, with 14 individual breeding females identified at Logans Beach. Twenty-one individual females were sighted east of Warrnambool in at least one season: 5 in the Great Ocean Road area, 3 near Wilson's Promontory, 10 off Flinders Island and the east coast of Tasmania, and 3 in New South Wales (Fig. 2).

The second superpopulation markrecapture model, based on breeding females only, revealed that the estimated population of southern right whale females that have used the southeastern Australian coastline for calving has increased from 2 (95\% credible interval
[CI]: 1-11) in 1985 to 68 (37-165) in 2017 (Fig. 3). Applying the International Whaling Commission (IWC) accepted conversion factor of 3.94 to convert estimates of mature females to the total number of individuals in a population (IWC 2013) produced a total population estimate of 268 (146-650) in 2017. The annual growth rate (using the geometric mean) from 1996 to 2017 was $4.7 \%(2.3-7.3 \%)$. The growth rate from 1985 to 2017 was higher $(10.9 \%, 95 \%$ CI: $6.8-15.3 \%)$ but there was a large degree of inconsistency in popula-

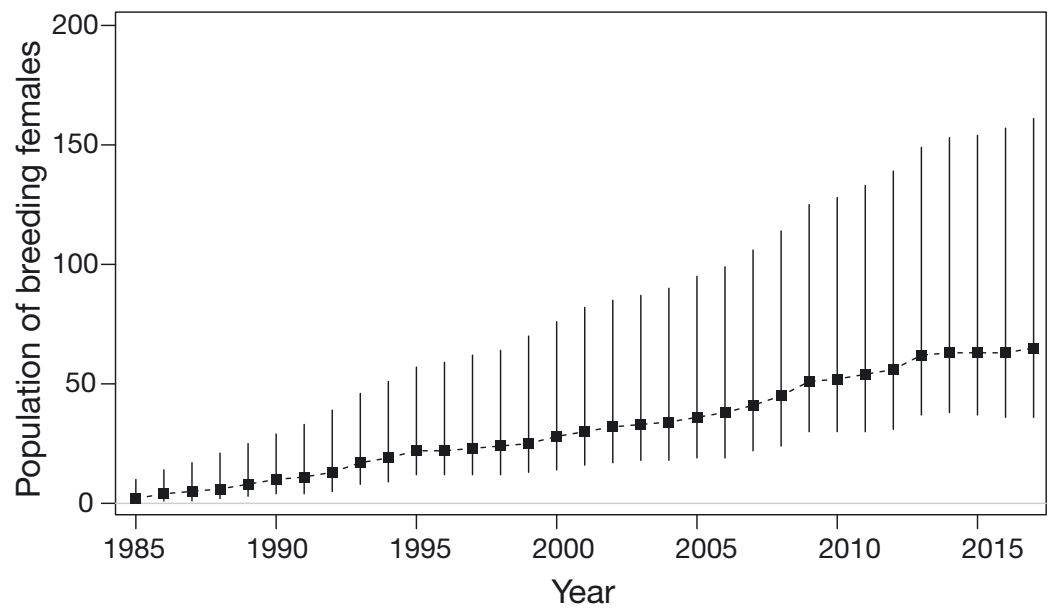

Fig. 3. Southern right whale breeding female population estimated with a superpopulation mark-recapture model. Vertical lines show $95 \%$ credible intervals 
tion size in the first $10 \mathrm{yr}$, so the more recent estimate was deemed more reliable.

The mean survival rate for breeding females was estimated at $97 \%$ (95\% CI: 93-99\%). The estimated annual capture probability was $19 \%(1-68 \%)$. The probability of a breeding female returning since its previous visit increased as more time elapsed since the last visit (see Fig. S2 in Supplement 1). The odds of a breeding female returning since its previous visit increased by a factor of 2.4 (1.5-4.3) each year away, given they were still alive.

\subsection{Bayesian sightings trend model}

\subsubsection{Trends in sightings along the southeastern Australian coastline}

The median annual increase in the average number of southern right whales (all adults and calves) using the southeastern Australian coastline was esti-
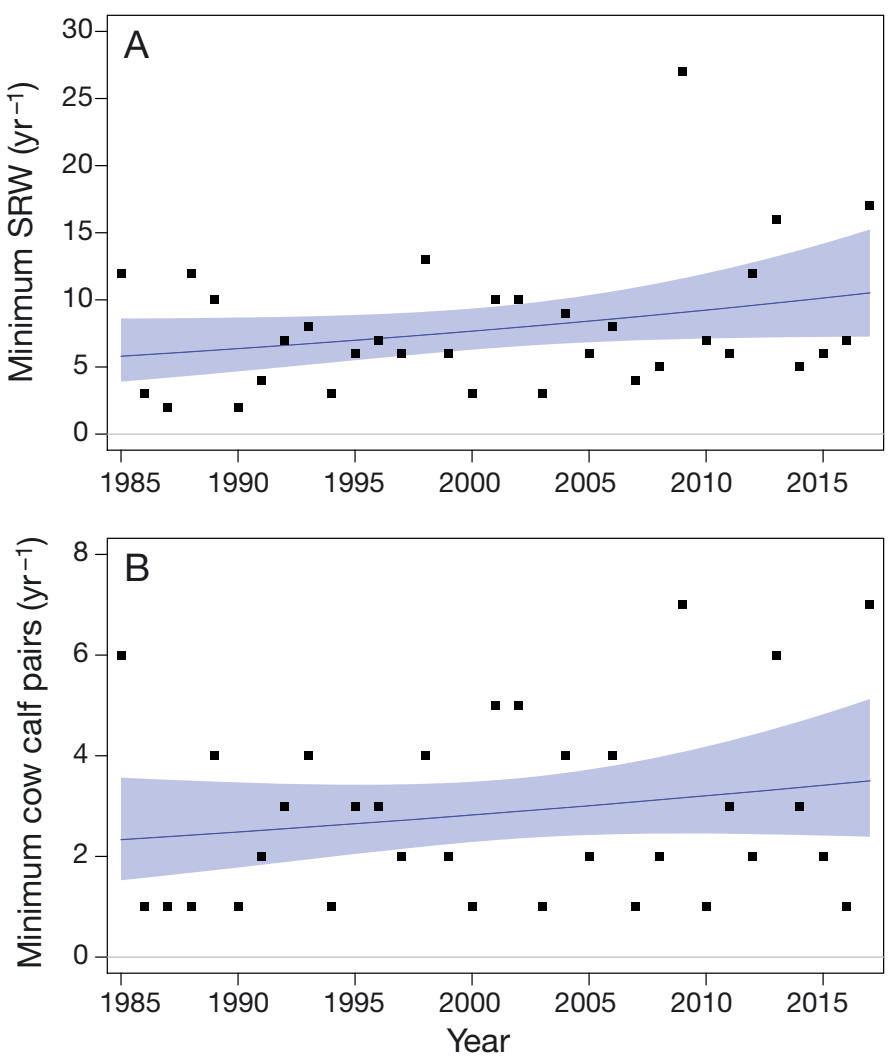

Fig. 4. (A) Minimum number of southern right whales (SRW) observed in southeastern Australia (1985-2017). (B) Minimum number of SRW mother-calf pairs observed in southeastern Australia that have used Logans Beach as a nursery ground for at least one season. The blue line indicates the expected value, while the shaded area shows the 95\% credible interval mated at $7.3 \%$ (95\% CI: 4.1-9.4\%) (Fig. 4A). There was an estimated increase from 5 (3-8) southern right whales in 1985 to $41(27-63)$ in 2017.

\subsubsection{Trends in mother-calf pairs at Logans Beach}

There is insufficient evidence to conclude that the annual number of mother-calf pairs using the Logans Beach nursery has increased between 1985 and 2017. While the observation model estimated that the annual number of mother-calf pairs increased from 2.5 (95\% CI: $1.5-3.7)$ in 1985 to $3.1(1.9-4.7)$ in 2017 (Fig. 4B), the $95 \% \mathrm{CI}$ for the average annual increase $(1 \%)$ included zero $(95 \% \mathrm{CI}:-2-3 \%)$; therefore, it was not significant.

\subsection{Theoretical population model}

The theoretical population model for Logans Beach breeding females showed an expected growth rate of $4 \%$ per annum (95\% CI: $2-5 \%$ ). Depending on the initial number of mature females that used Logans Beach in 1980, the 2018 breeding female population ranged from $5(0-14)$ starting with a single breeding female in 1980 to 74 (46-105) starting with 15 breeding females in 1980 (Fig. 5B). Given an initial population of 4 southern right whale breeding females in 1980 , the 2018 breeding female population would be expected to be $19(6-37)$, while in 2028 it would be expected to be $28(9-55$; Fig. $5 \mathrm{~A})$. The number of breeding females currently using Logans Beach for nursing calves during winter is 14 .

\section{DISCUSSION}

This study provides the first estimate of population abundance and rate of increase for the southeastern Australian southern right whale population. Our analysis found a 3 to 5 yr cycle in population spikes, with the probability of returning peaking between 3 and $5 \mathrm{yr}$, consistent with the current understanding of female breeding cycles (Burnell 2001, Bannister 2011, Charlton 2017). The abundance estimate of 268 individuals for the southeastern management unit of southern right whales provides an update to the inconclusive estimate of 257 individuals completed in 2014 (Watson et al. 2015). The estimate of 268 whales for the southeastern Australian coastline is well below the estimate for the southwest of the continent (Bannister 2018). However, the current rate of increase of 

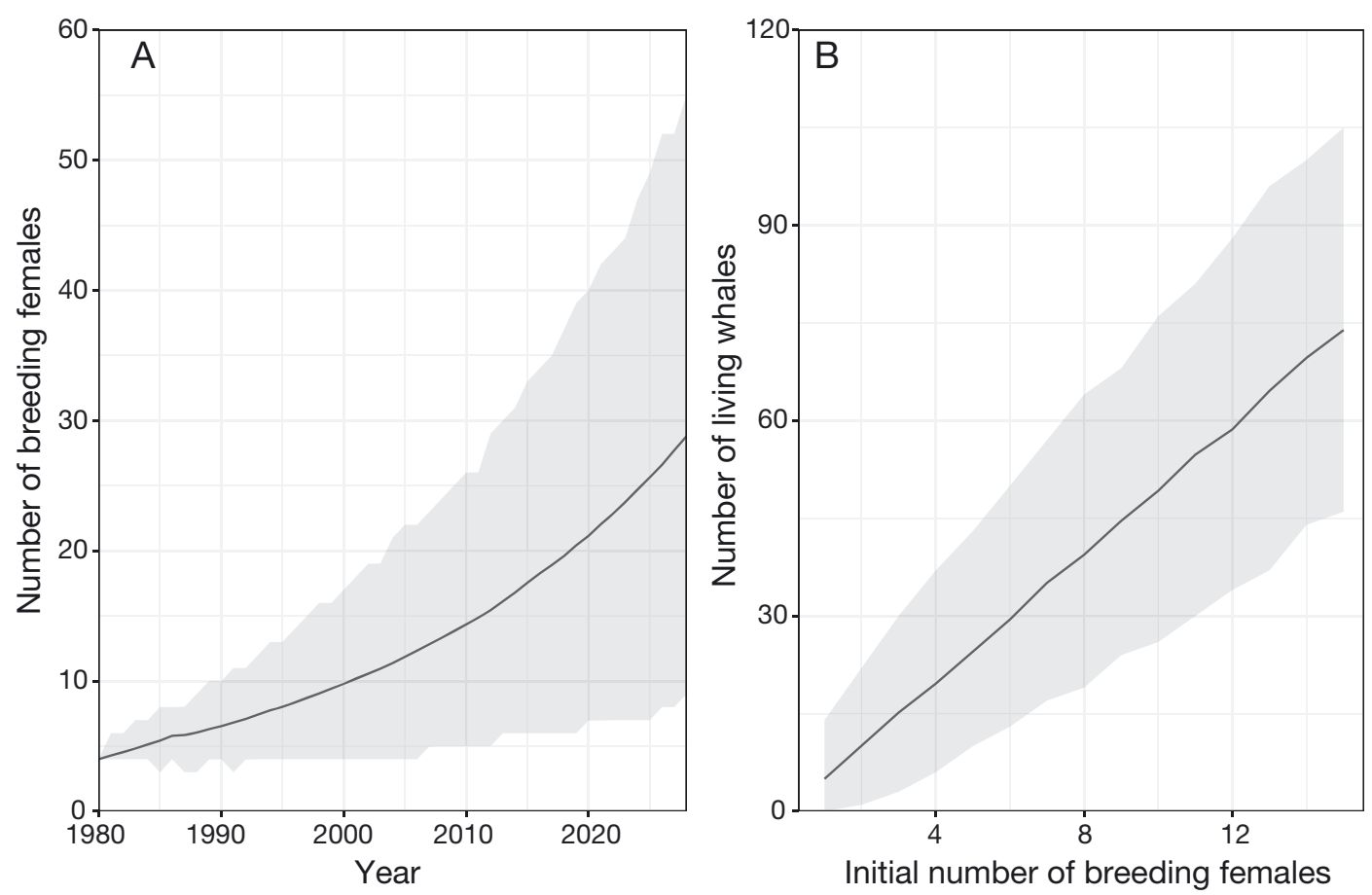

Fig. 5. (A) Temporal changes in the theoretical southern right whale breeding female population at Logans Beach, assuming an initial number of 4 breeding females in 1980. (B) Theoretical southern right whale breeding female population at Logans Beach in 2018 as a function of the initial number of breeding females in 1980

reproductive females $(4.7 \%)$, while lower than that of the southwestern population $(6.2 \%, 95 \% \mathrm{CI}$ : $3.9-8.6 \%)$, falls within the bounds of its confidence interval (Bannister 2018). The rate of increase reported here is very similar to that of the New Zealand population between 2006 and $2016(4.8 \%, 95 \% \mathrm{CI}$ : 2.4-6.4\%; Davidson et al. 2016). Elsewhere (e.g. South Africa and Argentina), southern right whales are increasing at or near the estimated biological maximum rate of increase for the species $(6-7 \%$ per annum; Brandão et al. 2011, IWC 2013).

Despite an increase in breeding females sighted in southeastern Australia between 1985 and 2017 (Fig. 3), there is no evidence of an increase in annual numbers of mother-calf pairs at the only recognised aggregation ground for this population. These results support previous notions that the southeastern Australian management unit is taking longer to recover than the southwestern Australian management unit. This difference is likely the result of a higher incidence of local extirpation of breeding females in southeastern Australia and a consequent loss of memory of calving areas (Carroll et al. 2015). The practice of shore-based whaling inherently targeted females and calves, and historic records show that shore-based whaling pressure was much greater in the southeastern Australian region than the southwestern Australian region (Pirzl 2008).
As there is considerable overlap in the wintering range of individuals belonging to the southeastern and southwestern management units (Carroll et al. 2015, M. Watson unpubl. data), deriving population estimates based on the number of whales seen along the southeastern Australian coast is difficult. Restricting the analysis to mother-calf pairs sighted prior to the beginning of the southward migration reduced the likelihood of including a breeding female from the southwestern population transiting through the east. There is a possibility (albeit small) that a female from the southwestern population may have given birth in the east en route to the southwestern nursery grounds or left the southwestern breeding grounds early. Two females included in this analysis were sighted in the southwestern region when cross-matched to data in the ARWPIC. One of these females had been sighted in the southwestern region for 4 seasons (including with a calf at Head of Bight in 2000) before she was sighted moving west along the Victorian coast with a calf on 31 July and 1 August 2008. It is possible that this whale was travelling to the southwestern nursery ground. The second female sighted in both the southeastern and southwestern management units had calved at Logans Beach at least 7 times over a $17 \mathrm{yr}$ period before shifting to calve at Head of Bight in South Australia (southwestern management 
unit) for 4 consecutive calving events over $10 \mathrm{yr}$ (M. Watson unpubl. data).

While the number of whales (adults and calves) using southeastern Australia during the entire whale-watching season is increasing by $7.3 \%$ annually (Fig. 5), it is possible that the increase of the southwestern management unit is partly responsible for the increase in whales seen in southeastern Australia (i.e. an increase in whales from the southwestern management unit transiting through southeastern Australian waters to and from their calving grounds in the west). While the high degree of mixing between populations in the southeastern Australian migration corridor complicates the determination of trends for the southeastern Australian population, observational data can still provide valuable information on the usage of the southeastern Australian coastline by southern right whales. A more targeted effort to collect data systematically across the entire southeastern Australian coastline (i.e. via aerial surveys) will improve our ability to detect usage patterns over time. Changes in the geographic distribution of southern right whales along the Argentinian coast have been uncovered using this approach (e.g. Arias et al. 2018). A study is underway to use photo-identification mark-recapture data from the ARWPIC to estimate the abundance of the Australian population.

Assessing trends in mother-calf pairs at known calving grounds is likely to provide the most useful information for management of the southeastern Australian southern right whale management unit. We show that there has been no significant increase in the average number of calves born annually at Logans Beach over the last 3 decades (Fig. 4B). The current number of breeding females (14) that have used Logans Beach for nursing calves during winter is lower than the prediction from the theoretical population model (19), but falls within the credible intervals of this prediction. Southern right whales are long-lived, take a long time to mature and have long calving intervals (Burnell 2001, Charlton 2017). Thus, it is likely to take more time before we see a significant increase in the number of calves born at Logans Beach. Under the assumption of 4 breeding females in 1980, the theoretical model predicts that by 2028 we should see 28 breeding females using Logans Beach. This prediction provides a useful monitoring benchmark. Our model also assumes female calves will return to Logans Beach to calve once mature, a reasonable assumption given that southern right whales show strong natal site fidelity (Burnell 2001, Rowntree et al. 2001, Carroll et al. 2015, 2016, Charl- ton 2017). However, the model does not consider the saturation capacity of the area, which is currently unknown, or usage patterns outside of Logans Beach. The availability of suitable breeding habitat could be a limiting factor in the population's recovery and is something that needs to be monitored.

A monitoring program should include regular surveys of the entire southeastern Australian coastline to identify emerging aggregation areas or evidence of range expansion. Historically, high-use areas for southern right whales in southeastern Australia included southeastern Tasmania, southern New South Wales and southwestern Victoria (DSEWPaC 2012). Although currently only one nursery ground is known in southeastern Australia, we have identified 21 females with calves elsewhere in southeastern Australian waters during the calving period. It is possible that other areas in the eastern Australian region are being used for calving and nursing.

A major limitation of our overall superpopulation mark-recapture model was that we could only include years where data from both the southeastern and southwestern Australian management units were available in the ARWPIC (1993-2011). More data may be required to build a more reliable superpopulation mark-recapture model, including data from 2011 onwards and from the South Australian photo-identification catalogues. In addition, many individuals in the overall superpopulation markrecapture model were only observed once. Of the 199 individuals detected from 1993 to 2011, 170 were sighted once. With such a large number of transient southern right whales sighted in southeastern Australia (or such a large number going undetected), it would seem that a more restrictive definition is required to delineate any patterns in the southeastern Australian population. The presence of transients may not be as important for the breeding female superpopulation mark-recapture model, where most individuals were sighted more than once.

Furthermore, some of the variability within the model was due to inconsistencies in the data collection and detection. At Logans Beach where observer effort is high, the detection rate of mother-calf pairs may be close to $90-100 \%$. Elsewhere within the wintering range of the southeastern Australian population, observer effort is more sporadic and it is likely that some mother-calf pairs remained undetected. Without any measure of effort these differences cannot be corrected, and may bias the model towards the properties of those whales that spend time at Logans Beach. More intensive monitoring of the southeastern Australian region and cross- 
matching of data from the whole Australasian region is needed to improve detection rates.

This study provides the first complete estimate of population size and rate of increase of the southeastern Australian southern right whale population. It has given us a long-term theoretical model of breeding females at Logans Beach, a benchmark against which we can measure future observations. The population is showing promising signs of increase, but to detect population responses to current and future environmental stressors, monitoring of abundance and temporal and spatial distribution needs to persist into the future.

Acknowledgements. We are grateful to the volunteers and government staff across Victoria, South Australia, Tasmania and New South Wales who have contributed to the catalogues. Much of the data from the 1990s was provided by Dr. Stephen Burnell of Eubalaena. Rachel Alderman coordinated the incorporation of Tasmanian data into ARWPIC. We thank Robert Harcourt (Macquarie University) and Nathalie Patenaude (Collégial International Sainte-Anne) for contributing photo-identification data from southeastern Australia. Technical support for ARWPIC was provided by the Australian Marine Mammal Centre, in particular Virginia Andrews-Goff, Andy Townsend and Mike Double, as well as Keiren Lawton from Skadia. Comments from Peter Menkhorst (Arthur Rylah Institute for Environmental Research), Emma Carroll (University of Auckland) and professional editor Lucie Bland greatly improved earlier drafts of the manuscript. Funding for the matching between the SEA SRW PIC and ARWPIC was provided by the Victorian Government's 2015 Threatened Species Protection Initiative (TSPI). Co-author John Bannister passed away during the write up of the manuscript. The authors thank John for his contribution to this paper and to southern right whale research, as well as for his mentoring and friendship.

\section{LITERATURE CITED}

Arias M, Coscarella MA, Romerao MA, Sueyro N, Svendsen GM, Crespo EA, Gonzalez RA (2018) Southern right whale Eubalaena australis recolonizes Golfo San Matias (Patagonia, Argentina). International Whaling Commission document SC/67B/CMP/01

Bannister JL (1990) Southern right whales off Western Australia. https://open.uct.ac.za/handle/11427/18863 (accessed 16 Apr 2020)

Bannister J (2011) Population trend in right whales off southern Australia 1993-2010. Southern right whale assessment workshop: Buenos Aires, 13-16 September 2011. International Whaling Commission document SC/S11/RW10IWC

Bannister JL (2018) Monitoring population dynamics of 'western' right whales off southern Australia 20152018 - final report on activities for 2017. Report to the National Environmental Science Programme, Marine Biodiversity Hub. Western Australian Museum (lead organisation). www.nespmarine.edu.au/system/files/Bannister
\%20A7 \% 20Monitoring \% 20population \% 20dynamics \% 20Final\%20report\%20on\%202017\%20activities_30\%20 March\%202018_Milestone\%206\%20RPv3\%202017_AO_ NB.pdf (accessed 16 Apr 2020)

Best PB (1990) Natural markings and their use in determining calving intervals in right whales off South Africa. S Afr J Zool 25:114-123

Brandão A, Best PB, Butterworth DS (2011) Monitoring the recovery of the southern right whale in South African waters. International Whaling Commission document SC/S11/RW18

Brandão A, Butterworth D, Muller A, Best PB (2013) Application of a photo-identification based assessment model to southern right whales in South African waters. Report SC/64/BRG24 presented to the Scientific Committee of the International Whaling Commission, Cambridge. https://open.uct.ac.za/handle/11427/18863 (accessed 16 Apr 2020)

Brooks SP, Gelman A (1998) General methods for monitoring convergence of iterative simulations. J Comput Graph Stat 7:434-455

* Bürkner PC (2017) brms: An R package for Bayesian multilevel models using Stan. J Stat Softw 80:1-28

Burnell SR (2001) Aspects of reproductive biology, movements and site fidelity of right whales off Australia. J Cetacean Res Manag Spec Issue 2:89-102

* Carroll EL, Patenaude N, Alexander A, Steel D and others (2011a) Population structure and individual movement of southern right whales around New Zealand and Australia. Mar Ecol Prog Ser 432:257-268

Carroll EL, Patenaude N, Childerhouse S, Kraus SD, Fewster RM, Baker CS (2011b) Abundance of the New Zealand subantarctic southern right whale population estimated from photo-identification and genotype markrecapture. Mar Biol 158:2565-2575

* Carroll EL, Jackson JA, Paton D, Smith TD (2014) Two intense decades of 19th century whaling precipitated rapid decline of right whales around New Zealand and east Australia. PLOS ONE 9:e93789

* Carroll EL, Baker CS, Watson M, Alderman R and others (2015) Cultural traditions across a migratory network shape the genetic structure of southern right whales around Australia and New Zealand. Sci Rep 5:16182

Carroll EL, Fewster RM, Childerhouse SJ, Patenaude NJ, Boren L, Baker CS (2016) First direct evidence for natal wintering ground fidelity and estimate of juvenile survival in the New Zealand southern right whale Eubalaena australis. PLOS ONE 11: e0146590

Caswell H, John AM (1992) From the individual to the population in demographic models. In: DeAngelis DL, Gross LJ (eds) Individual based models and approaches in ecology. Chapman and Hall, New York, NY, p 36-61

Charlton CM (2017) Population demographics of southern right whales (Eubalaena australis) in Southern Australia. PhD dissertation, Curtin University, Bentley, Western Australia

Davidson A, Rayment W, Slooten, E (2016) Population dynamics of New Zealand southern right whale (Eubalaena australis) International Whaling Commission document SC/67A/SH/08

DSEWPaC (Department of Sustainability, Environment, Water, Population and Communities) (2012) Conservation management plan for the southern right whale: a recovery plan under the Environment Protection and Biodiversity Conservation Act 1999 2011-2021. Depart- 
ment of Sustainability, Environment, Water, Population and Communities, Canberra

Félix F, Castro C, Laake JL, Haase BEN, Scheidat M (2011) Abundance and survival estimates of the southeastern pacific humpback whale stock from 1991-2006 photoidentification surveys in Ecuador. J Cetacean Res Manag Spec Issue 3:301-307

IWC (International Whaling Commission) (2013) Report of the workshop on southern right whales. International Whaling Commission document SC/65A/Rep05

Jackson JA, Patenaude NJ, Carroll EL, Baker CS (2008) How few whales were there after whaling? Inference from contemporary mtDNA diversity. Mol Ecol 17: 236-251

Kemper C, Mole J, Warneke RM, Ling JK, Needham DJ, Wapstra JE (1997) Southern right whales in southeastern Australia - aerial surveys during 1991-93 and incidental information from 1904. In: Hindell M, Kemper C (eds) Marine mammal research in the Southern Hemisphere, Vol 1: Status, ecology, and medicine. Surrey Beatty \& Sons, Chipping Norton, p 40-55

Kéry M (2010) Introduction to WinBUGS for ecologists: Bayesian approach to regression, ANOVA, mixed models and related analyses. Academic Press, Orlando, FL

Payne R, Brazier O, Dorsey E, Perkins J, Rowntree V, Titus A (1983) External features in southern right whales (Eubalaena australis) and their use in identifying individuals. In: Payne $\mathrm{R}$ (ed) Communication and behaviour of whales. Westview Press, Boulder, CO, p 371-445

Pirzl R (2008) Spatial ecology of Eubalaena australis: habitat selection at multiple scales. PhD dissertation, Deakin University, Burwood, Victoria

R Core Team (2018) R: a language and environment for statistical computing (Version 3.4.4). R Foundation for Statistical Computing, Vienna

Rowntree VJ, Payne R, Schell DM (2001) Changing patterns of habitat use by southern right whales (Eubalaena australis) on their nursery ground at Península Valdés,

Editorial responsibility: B. Louise Chilvers,

Palmerston North, New Zealand
Argentina, and in their long-range movements. J Cetacean Res Manag Spec Issue 2:133-143

Schwarz CJ, Arnason AN (1996) A general methodology for the analysis of capture-recapture experiments in open populations. Biometrics 52:860-873

Smith J, Jones D, Travouillon K, Kelly N, Double M, Bannister JL (2019) Monitoring population dynamics of 'western' right whales off southern Australia 2018-2021final report on activities for 2018. Report to the National Environmental Science Program, Marine Biodiversity Hub. Western Australian Museum (lead organisation). www. nespmarine.edu.au/document/monitoring-populationdynamics-\%E2 \% 80\%98western \% E2 \% 80\%99-rightwhales-southern-australia-2018-2021-final (accessed 16 Apr 2020)

Su YS, Yajima M (2012) R2jags: a package for running jags from R. R package version 0.03-08, http://CRAN. R-project.org/package $=\mathrm{R} 2$ jags

Teerlink SF, von Ziegesar O, Straley JM, Quinn TJ II, Matkin CO, Saulitis EL (2015) First time series of estimated humpback whale (Megaptera novaeangliae) abundance in Prince William Sound. Environ Ecol Stat 22:345-368

Tyne JA, Pollock KH, Johnston DW, Bejder L (2014) Abundance and survival rates of the Hawai'i Island associated spinner dolphin (Stenella longirostris) stock. PLOS ONE 9: e86132

Victorian Government Department of Sustainability and Environment (2013) Advisory list of threatened vertebrate fauna in Victoria. Victorian Department of Sustainability and Environment, Melbourne

Watson M, Westhorpe I, Bannister J, Harcourt R, Hedley S (2015) Australian marine mammal centre grants program final report for project 13/29: Assessment of numbers and distribution of southern right whales in south-east Australia - Year 2. The Australian Marine Mammal Centre, Hobart

Zuur AF, Ieno EN, Smith GM (2007) Analysing ecological data. Springer, New York, NY

Submitted: May 22, 2019; Accepted: February 13, 2020 Proofs received from author(s): April 18, 2020 